\title{
STUDY OF THE INHERITANCE OF SOME DAILY LIFE HABITS
}

\author{
F. CONTERIO and B. CHIARELLI*
}

Department of Genetics, Parma and Department of Genetics, Pavia.

Received $16 . x i .61$

\section{INTRODUCTION}

THE purpose of this work is an analysis of the role of inheritance in determining some habits of everyday life. The method used was the study of the concordance of such habits in pairs of monozygous and dizygous twins.

Sir Ronald Fisher (1958a) has observed greater concordance between pairs of male monozygous twins regarding smoking habits.

Similar results have been obtained by the same author (1958b) on pairs of female twins and no considerable effect of the mutual influence was observed because the $\mathrm{MZ}$ girl twins which were separated at birth behaved, regarding to smoking-habits, in the same manner as those who always lived together.

A detailed report was published by Todd and Mason (1959) on the smoking habits of the twins which were included in the register of twins of the Institute of Human Genetics at Münster, collected from the cities of Tubingen, Berlin and Frankfurt am Main. These authors found a higher concordance of smoking habits in monozygous twins both as to quantity and quality of the smoked products.

Another investigation, on the consumption of alcohol was carried out in Sweden by Kaij (1957) and gave similar results to the above.

We have started a similar investigation of smoking and alcohol drinking habits on 77 pairs of twins of the male sex living in the towns of Parma, Pavia and Florence. Moreover, this investigation was extended to another habit which is quite common in Italy: the consumption of coffee.

\section{MATERIAL AND METHODS}

Names and addresses of twins both of the male sex were collected through the Town Hall Registers of Parma, Pavia and Florence. Only individuals over twenty years of age were considered. Members of pairs were interviewed separately and were asked a number of questions according to a standard questionnaire which is given as Appendix I. In addition to questions on the clinical history of the persons, on the history of smoking habits and of alcohol and coffee consumption, some other questions were added, designed to ascertain how long the twins lived together, if they went to school together, and how close was the association of the two twins. Such questions have the aim of establishing the possible reciprocal influence of

* This investigation was supported by a grant from the Tobacco Manufacturers' Standing Committee, London. 
twins, and always to this end every person interviewed was asked if he considered himself satisfied with being a twin. Anthropometrical measurements were also taken as listed in table $\mathrm{I}$, as were finger-prints, photographs, systolic and diastolic pressure and blood samples.

\section{TABLE I}

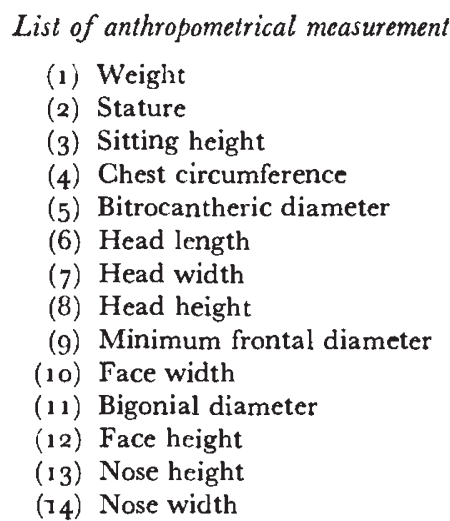

The 77 pairs of twins were distributed as follows : 24 from the town of Parma, 19 from Pavia and 34 from Florence.

Blood groups were assayed with the following sera: anti-A, anti- $A_{1}$, anti-B, five anti-Rh sera (anti-C, anti-c, anti-D, anti-E, anti-e) except for a few pairs which were assayed only with anti-D, anti-M and anti-N. Of the 77 pairs 30 had identical blood groups, 24 had different blood groups and of the remaining 23 pairs either one member of the pair or both refused to give blood. A discrimination between monozygous and dizygous pairs was thus necessary both for the twins of equal blood groups as well as for those which were not typed.

The method given by Maynard Smith and Penrose (1955) for individuals of equal blood group did not prove satisfactory in the present case, because the probabilities obtained were not sufficiently different from one pair to the other. An attempt was therefore made to solve the problem by using the anthropometrical measurements taken for evaluating the degree of similarities between the members of the pairs.

To this end we have calculated a discriminant according to the method suggested by Penrose (1947 and 1954), giving the best combination of these measurements for a discrimination between the two groups of twin pairs, those with similar and those with dissimilar blood groups. Even this method left us with some uncertainty concerning nine pairs which were classified on the basis of an evaluation of resemblance using photographs and finger-prints.

Of 77 pairs of twins examined, 34 were classified as monozygous and 43 as dizygous.

\section{SMOKING HABITS}

Every individual was asked about his present and past habits of smoking. The individuals could thus be classified as in table 2, using a criterion similar to the one employed by Todd. From this table one can see that on an average monozygous twins smoke a little more than dizygous individuals. The same tendency can be noted in the data used by Todd, but the difference is not significant in his case. 
The explanation of this fact is not easy but it should not alter our conclusions. The concordance between pairs of monozygous and dizygous twins has been tested by means of four methods of analysis.

TABLE 2

Classification for the smoking habits of twins

\begin{tabular}{|c|c|c|c|c|}
\hline Code & \multicolumn{2}{|c|}{ Classification } & $\begin{array}{l}\text { Monozygous } \\
\text { individuals }\end{array}$ & $\begin{array}{c}\text { Dizygous } \\
\text { individuals }\end{array}$ \\
\hline \multirow{3}{*}{$\begin{array}{l}0 \\
1 \\
2\end{array}$} & \multirow{12}{*}{$\begin{array}{l}\text { Never smoked } \\
\text { Stopped smoking } \\
\text { Occasional smoking (less th } \\
\text { I pipe a day or I cigar a } \\
\text { I-5 cigarettes a day } \\
6-20 \text { cigarettes a day } \\
>20 \text { cigarettes a day } \\
\text { Pipe } \\
\text { Cigar } \\
\text { Mixed cigarettes and pipe } \\
\text { Mixed cigaretes and cigars } \\
\text { Mixed cigars and pipe }\end{array}$} & \multirow{3}{*}{ i cigarette or } & 3 & 17 \\
\hline & & & $\ldots$ & 7 \\
\hline & & & 3 & 5 \\
\hline \multirow{9}{*}{$\begin{array}{r}3 \\
4 \\
5 \\
6 \\
7 \\
8 \\
9 \\
10\end{array}$} & &.$\quad$. & II & II \\
\hline & & & 43 & 28 \\
\hline & & & 6 & 16 \\
\hline & & . & 2 & $\ldots$ \\
\hline & & . & $\ldots$ & I \\
\hline & & . & $\ldots$ & I \\
\hline & & . & $\ldots$ & $\ldots$ \\
\hline & & . & $\ldots$ & $\ldots$ \\
\hline & & & 68 & 86 \\
\hline
\end{tabular}

\section{(i) Analysis of smokers versus non-smokers}

In this analysis, occasional smokers were considered smokers while non-smokers were considered those who had never smoked and those who had stopped smoking. This analysis gave the results shown in table $3 ; \chi_{[1]}^{2}$ for independence is $5.8 \mathrm{I} 7$ with $\mathrm{P}<0.02$. Yates' correction for continuity has been used throughout in the calculation of $\chi^{2}$.

TABLE 3

Analysis of smokers versus non-smokers

\begin{tabular}{|c|c|c|c|}
\hline \multicolumn{2}{|c|}{ Smoking habits } & $\mathrm{MZ}$ & $\mathrm{DZ}$ \\
\hline \multirow[t]{2}{*}{$\begin{array}{l}\text { Like } \\
\text { Unlike }\end{array}$} & \multirow[t]{2}{*}{. } & $\begin{array}{r}3 \mathrm{I} \\
3\end{array}$ & $\begin{array}{l}28 \\
15\end{array}$ \\
\hline & & 34 & 43 \\
\hline
\end{tabular}

(ii) Analysis of regular smokers and irregular smokers

In this case, irregular smokers, those who had stopped smoking, or are occasional smokers were considered. This analysis is given in table 4. $\chi_{[1]}^{2}$ for independence is 4.20 with $\mathrm{P}<0.05$. 
TABLE 4

Analysis of regular and irregular smokers

\begin{tabular}{|c|c|c|c|}
\hline \multicolumn{2}{|c|}{ Smoking habits } & MZ & $\mathrm{DZ}$ \\
\hline \multirow[t]{2}{*}{$\begin{array}{l}\text { Like } \\
\text { Unlike }\end{array}$} & \multirow[t]{2}{*}{$\cdot$} & $\begin{array}{r}28 \\
6\end{array}$ & $\begin{array}{l}25 \\
18\end{array}$ \\
\hline & & 34 & 43 \\
\hline
\end{tabular}

(iii) Analysis according to quantity of smoked products

In this analysis those who were included in the same classification are considered as similar (in practice those who are classified with the same code number) $\chi_{[1]}^{2}$ for independence is $12 \cdot 916$ with $\mathrm{P}<0 \cdot 001$.

TABLE 5

Analysis according to quantity of smoked products

\begin{tabular}{|c|c|c|c|}
\hline \multicolumn{2}{|c|}{ Smoking habits } & MZ & DZ \\
\hline \multirow[t]{2}{*}{$\begin{array}{l}\text { Like } \\
\text { Unlike }\end{array}$} & \multirow[t]{2}{*}{. } & $\begin{array}{r}26 \\
8\end{array}$ & $\begin{array}{l}14 \\
29\end{array}$ \\
\hline & & 34 & 43 \\
\hline
\end{tabular}

(iv) Analysis of inhalers versus non-inhalers

It is also interesting to notice the behaviour of twins regarding a very common habit among smokers: inhaling the smoke. The analysis of similarity in twins for inhaling habits gave the data in table 6 , showing a significantly higher concordance for $M Z$ twins $\left(\chi_{[1]}^{2}=6 \cdot 800\right)$.

TABLE 6

Analysis of inhalers versus non-inhalers

\begin{tabular}{|c|c|c|c|}
\hline \multicolumn{2}{|c|}{ Inhaling habits } & $\mathrm{MZ}$ & $\mathrm{DZ}$ \\
\hline \multirow[t]{2}{*}{$\begin{array}{l}\text { Like } \\
\text { Unlike }\end{array}$} & \multirow{2}{*}{ : } & $\begin{array}{r}28 \\
6\end{array}$ & $\begin{array}{l}22 \\
21\end{array}$ \\
\hline & & 34 & 43 \\
\hline
\end{tabular}

The inhaling habit is commoner among cigarette smokers and the difference between $\mathrm{MZ}$ and $\mathrm{DZ}$ twins is not significant for this habit: in fact $5^{\mathrm{I}} \mathrm{MZ}$ twins out of 60 ( 85 per cent.) were inhalers, and $39 \mathrm{DZ}$ twins out of $4^{8}$ were included in the same class $\left(\chi_{[1]}^{2} 0 \cdot 068, P>0 \cdot 70\right)$. 
The analysis was therefore repeated taking only those pairs who are both cigarette smokers (table 7). The $\chi_{[1]}^{2}$ for independence

TABLE 7

Analysis of inhalers versus non-inhalers

\begin{tabular}{|c|c|c|c|c|c|}
\hline \multicolumn{4}{|c|}{ Inhaling habits } & $\mathrm{MZ}$ & $\mathrm{DZ}$ \\
\hline \multirow[t]{2}{*}{$\begin{array}{l}\text { Like } \\
\text { Unlike }\end{array}$} & \multirow[t]{2}{*}{ • } & \multirow[t]{2}{*}{$\dot{.}$} & \multirow[t]{2}{*}{$\dot{.}$} & $\begin{array}{r}27 \\
3\end{array}$ & $\begin{array}{r}17 \\
7\end{array}$ \\
\hline & & & & 30 & 24 \\
\hline
\end{tabular}

is 2.100 with $\mathrm{P} \sim 0 \cdot 10$. The difference in concordance between $\mathrm{MZ}$ and $\mathrm{DZ}$ twins is in the right direction but is not significant for these data.

\section{ALCOHOL DRINKING HABITS}

The consumption of alcohol was analysed in a similar way. The individuals were classified as in table 8.

TABLE 8

Classification according to alcohol drinking habits of twins

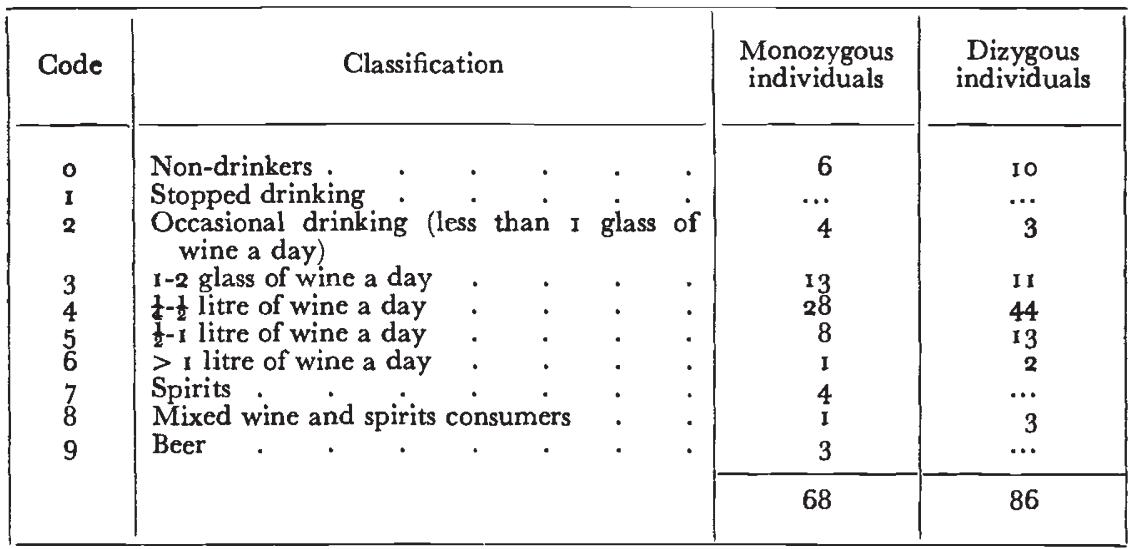

The concordance between pairs of monozygous and dizygous twins has been tested by three methods of analysis.

\section{(i) Analysis of drinkers of wine or of spirit versus non-drinkers}

In this analysis those who have never consumed wine or spirits and those who have stopped drinking are considered as non-drinkers. 
TABLE 9

Analysis of drinkers versus non-drinkers

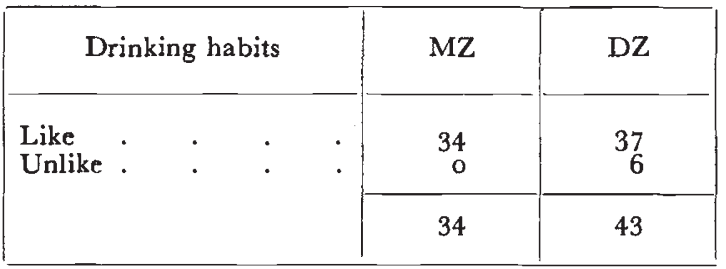

The $\chi_{[1]}^{2}$ value is 3.386 with $\mathrm{P}<0 \cdot 10$ and the difference in concordance between $\mathrm{MZ}$ and $\mathrm{DZ}$ twins is in the right direction but is not significant on these data.

\section{(ii) Analysis of wine-drinkers versus non-drinkers}

In this case those who have never drunk wine or consumed spirits or beer are considered as non-drinkers of wine. The $\chi^{2}$ value is not significant $\left(\chi_{[1]}^{2}=\mathrm{I} \cdot 109, \mathrm{P} \sim 0 \cdot 30\right)$.

TABLE 10

Analysis of wine-drinkers versus non-drinkers

\begin{tabular}{|c|c|c|c|}
\hline \multicolumn{2}{|c|}{ Drinking habits } & $\mathrm{MZ}$ & DZ \\
\hline \multirow[t]{2}{*}{$\begin{array}{l}\text { Like } \\
\text { Unlike }\end{array}$} & \multirow[t]{2}{*}{ 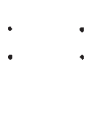 } & $\begin{array}{r}32 \\
2\end{array}$ & $\begin{array}{r}36 \\
7\end{array}$ \\
\hline & & 34 & 43 \\
\hline
\end{tabular}

(iii) Analysis according to the quantity of the alcoholic products consumed The $\chi^{2}$ value is not significant $\left(\chi_{[1]}^{2}=2 \cdot 440, \mathrm{P} \sim 0 \cdot 10\right)$.

TABLE II

Analysis according to the quantity of the alcoholic products consumed

\begin{tabular}{|c|c|c|c|}
\hline \multicolumn{2}{|c|}{ Drinking habits } & $\mathrm{MZ}$ & $\mathrm{DZ}$ \\
\hline \multirow[t]{2}{*}{$\begin{array}{l}\text { Like } \\
\text { Unlike }\end{array}$} & \multirow{2}{*}{. } & $\begin{array}{l}22 \\
12\end{array}$ & $\begin{array}{l}19 \\
24\end{array}$ \\
\hline & & 34 & 43 \\
\hline
\end{tabular}

\section{COFFEE CONSUMPTION}

Similar analyses were conducted for the consumption of coffee. The individuals could be classified as in table 12. The concordance 
TABLE 12

Classification according to the coffee-drinking habits in twins

\begin{tabular}{|c|c|c|c|}
\hline Code & Classification & $\begin{array}{l}\text { Monozygous } \\
\text { individuals }\end{array}$ & $\begin{array}{c}\text { Dizygous } \\
\text { individuals }\end{array}$ \\
\hline \multirow[t]{2}{*}{$\begin{array}{l}0 \\
1 \\
2 \\
3 \\
4 \\
5 \\
6 \\
7\end{array}$} & $\begin{array}{l}\text { Non-drinkers : } \\
\text { Stopped drinking }: \\
\text { Occasional drinking (less than } \\
\text { I }-2 \text { cups of coffee a day } \\
\begin{array}{l}\text { 3-5 cups of coffee a day } \\
\text { 3 } 5 \text { cups of coffee a day }\end{array} \\
\text { Substitutes } \\
\text { Mixed coffee and substitutes consumers }\end{array}$ & $\begin{array}{r}4 \\
\ldots \\
14 \\
24 \\
17 \\
7 \\
\cdots \\
2\end{array}$ & $\begin{array}{r}7 \\
\ldots \\
14 \\
34 \\
24 \\
5 \\
2 \\
\ldots\end{array}$ \\
\hline & & 68 & 86 \\
\hline
\end{tabular}

between pairs of monozygous and dizygous twins has been tested by three methods of analysis.

\section{(i) Analysis of coffee-drinkers versus non-drinkers}

This was conducted between those who have tried and those who have not tried to drink coffee, including in the latter class those who drink substitutes.

The difference in concordance between $\mathrm{MZ}$ and $\mathrm{DZ}$ twins is in the right direction, but is not significant on these data $\left(\chi_{[1]}^{2}=2.390\right.$, $P \sim 0 \cdot$ Io).

TABLE 13

Analysis of coffee-drinkers versus non-drinkers

\begin{tabular}{|c|c|c|c|c|}
\hline \multicolumn{3}{|c|}{ Drinking habits } & $\mathrm{MZ}$ & $\mathrm{DZ}$ \\
\hline \multirow[t]{2}{*}{$\begin{array}{l}\text { Like } \\
\text { Unlike }\end{array}$} & \multirow{2}{*}{\multicolumn{2}{|c|}{$\cdot \quad: \quad \cdot$}} & $\begin{array}{r}32 \\
2\end{array}$ & $\begin{array}{r}34 \\
9\end{array}$ \\
\hline & & & 34 & 43 \\
\hline
\end{tabular}

(ii) Analysis of regular and irregular coffee consumers

In this case the occasional coffee-drinkers are considered as irregular $\chi_{[1]}^{2}$ for independence is 7.729 with $\mathrm{P}<0.01$.

TABLE 14

Analysis of regular and irregular coffee consumers

\begin{tabular}{|c|c|c|c|}
\hline \multicolumn{2}{|c|}{ Drinking habits } & MZ & $\mathrm{DZ}$ \\
\hline \multirow[t]{2}{*}{$\begin{array}{l}\text { Like } \\
\text { Unlike }\end{array}$} & \multirow[t]{2}{*}{. } & $\begin{array}{r}29 \\
5\end{array}$ & $\begin{array}{l}23 \\
20\end{array}$ \\
\hline & & 34 & 43 \\
\hline
\end{tabular}


(iii) Analysis according to the quantity of coffee consumed

Here again $\chi_{[1]}^{2}$ is highly significant at a value of $17 \cdot 144$.

TABLE I5

Analysis according to the quantity of coffee consumed

\begin{tabular}{|c|c|c|c|c|}
\hline \multicolumn{3}{|c|}{ Drinking habits } & $\mathrm{MZ}$ & $\mathrm{DZ}$ \\
\hline \multirow[t]{2}{*}{$\begin{array}{l}\text { Like } \\
\text { Unlike }\end{array}$} & \multirow{2}{*}{\multicolumn{2}{|c|}{$: \quad: \quad:$}} & $\begin{array}{l}24 \\
10\end{array}$ & $\begin{array}{r}9 \\
34\end{array}$ \\
\hline & & & 34 & 43 \\
\hline
\end{tabular}

\section{SUMMARY OF THE ANALYSES}

The $\chi^{2}$ values calculated on the 77 pairs of twins are collected together in table 16 .

TABLE 16

Analysis between $M Z$ and $D Z$ twins

\begin{tabular}{|c|c|c|c|}
\hline & & $x_{[x]}^{2}$ & $\mathbf{P}$ \\
\hline $\begin{array}{l}\text { Analysis of smoking habits : } \\
\text { of smokers and non-smokers } \\
\text { of regular smakers and others } \\
\text { according to quantity of smoked products } \\
\text { of inhalers and non-inhalers }\end{array}$ & $\begin{array}{ll}\cdot & \dot{\cdot} \\
\cdot & \dot{*} \\
\cdot & \dot{\cdot}\end{array}$ & $\begin{array}{r}5 \cdot 817 \\
4 \cdot 201 \\
12 \cdot 916 \\
6 \cdot 800\end{array}$ & $\begin{array}{l}<0.02 \\
\sim 0.02 \\
<0.001 \\
<0.01\end{array}$ \\
\hline \multicolumn{2}{|c|}{$\begin{array}{l}\text { Analysis of alcohol-drinking habits : } \\
\text { of drinkers and non-drinkers of wine or of spirits . } \\
\text { of wine-drinkers and others } \\
\text { according to quantity of alcoholic products con- } \\
\text { sumed }\end{array}$} & $\begin{array}{l}3 \cdot 386 \\
1 \cdot 109 \\
2 \cdot 440\end{array}$ & $\begin{array}{l}<0 \cdot 10 \\
\sim 0 \cdot 30 \\
\sim 0 \cdot 10\end{array}$ \\
\hline $\begin{array}{l}\text { Analysis of coffee-drinking habits : } \\
\text { of drinkers and non-drinkers of coffee } \\
\text { of regular drinkers of coffee and others } \\
\text { according to quantity of coffee consumed }\end{array}$ & $\begin{array}{ll}\cdot & \cdot \\
\cdot & \cdot \\
\cdot & \cdot\end{array}$ & $\begin{array}{r}2 \cdot 390 \\
7 \cdot 729 \\
17 \cdot 144\end{array}$ & $\begin{array}{l}\sim 0.10 \\
<0.01 \\
<0.001\end{array}$ \\
\hline
\end{tabular}

The $\chi^{2} \mathrm{~s}$ are highly significant in respect of the differences in concordance between $\mathrm{MZ}$ and $\mathrm{DZ}$ pairs of twins for smoking habits and for coffee consumption. In respect of alcohol consumption there is a difference in concordance in the right direction, but not significant on these results.

These differences are also found separately in the three towns (Parma, Pavia and Florence) and they are similarly in the right direction, but the $\chi^{2}$ values are not always significant because in most cases the number of pairs examined in the individual town was too low. 


\section{AGE AND OTHER EFFECTS}

Distribution according to the age of the pairs of twins examined is shown in table 17 .

\section{TABLE $I 7$}

Age distribution of twins

\begin{tabular}{|c|c|c|c|c|c|c|c|c|}
\hline \multirow{2}{*}{$\begin{array}{c}\text { Age } \\
\text { classes }\end{array}$} & \multicolumn{3}{|c|}{ Monozygotic twins } & \multirow{2}{*}{ Total } & \multicolumn{3}{|c|}{ Dizygotic twins } & \multirow{2}{*}{ Total } \\
\hline & Parma & Pavia & Florence & & Parma & Pavia & Florence & \\
\hline $20-24$ & $\ldots$ & 3 & 2 & 5 & 3 & 2 & 8 & I3 \\
\hline 25 & 3 & 5 & 3 & II & 2 & $\ldots$ & 3 & 5 \\
\hline $30-$ & 3 & 2 & 3 & 8 & I & $\ldots$ & 3 & 4 \\
\hline $35-$ & 2 & I & 2 & 5 & I & I & 4 & 6 \\
\hline $4^{0-}$ & $\ldots$ & I & I & 2 & 4 & I & 2 & 7 \\
\hline $45-$ & I & $\ldots$ & $\ldots$ & 1 & $\ldots$ & I & .. & i \\
\hline $50-$ & $\ldots$ & $\ldots$ & $\ldots$ & $\ldots$ & $\cdots$ & 2 & 3 & 5 \\
\hline $55^{-}$ & 2 & $\ldots$ & $\ldots$ & 2 & I & $\ldots$ & $\ldots$ & I \\
\hline $60+$ & $\ldots$ & $\ldots$ & $\ldots$ & $\ldots$ & I & $\ldots$ & $\ldots$ & I \\
\hline Total & II & I 2 & II & 34 & I 3 & 7 & 23 & 43 \\
\hline
\end{tabular}

This distribution shows that the dizygotic twins included in our analysis are, on the average, older $(34.67 \pm 1 \cdot 78)$ than monozygotic twins $(32 \cdot 15 \pm 1 \cdot 15)$ though not significantly so. If, as might happen, the difference between twins tended to increase with the passing of time, the observed difference of average age between $\mathrm{DZ}$ and $\mathrm{MZ}$ twins would produce a greater difference in the habits of dizygotic pairs. To study this effect we analysed the concordance between $\mathrm{MZ}$ and $\mathrm{DZ}$ pairs of twins within age-groups, by subdividing them into two age-groups, from 20 to 29 years of age and from 30 to 60 respectively in order to obtain age-groups of approximately the same size.

The results of this analysis are shown in tables 18,19 and 20.

TABLE 18

Analysis according to quantity of smoked products within age groups

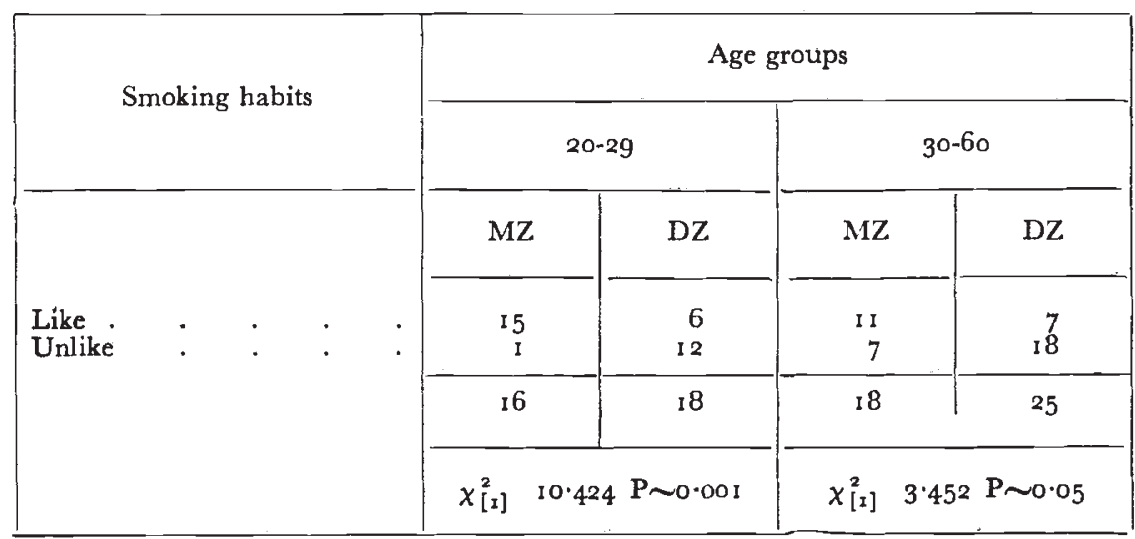


It appears evident from this analysis that age can have no material influence in accentuating the difference between $\mathrm{MZ}$ and $\mathrm{DZ}$ pairs of twins. In fact, while the $\chi^{2}$ values in the table for the consumption of coffee, computed with the observed pairs of twins separated into

TABLE 19

Analysis according to quantity of alcoholic products consumed within age groups

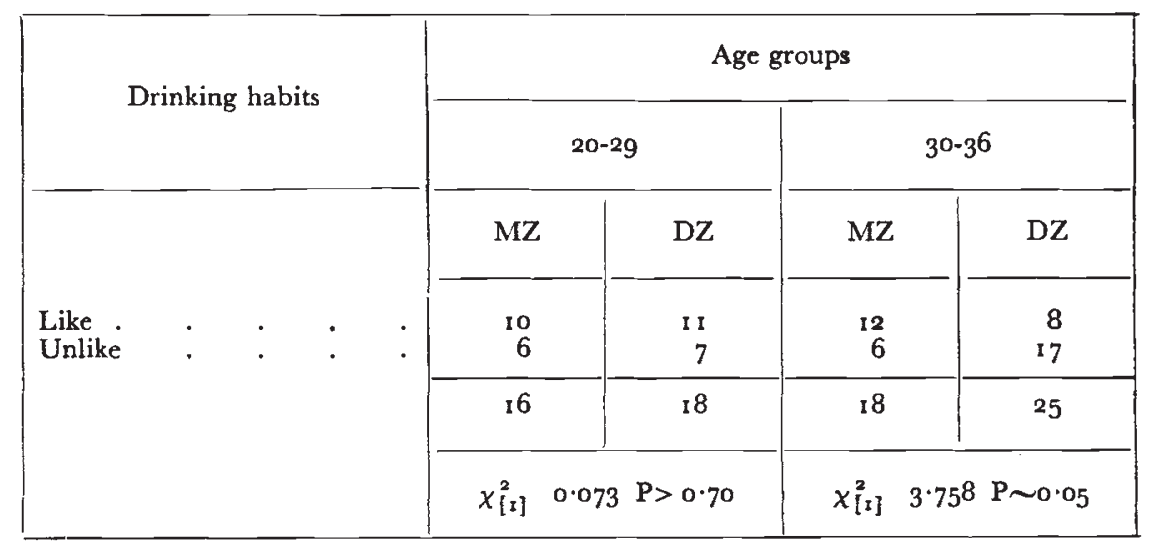

two age groups, are both highly significant, the $\chi^{2}$ value of twins between 20 and 29 in respect of the smoking habit appears to be even more highly significant. This may be explained by the fact that the

TABLE 20

Analysis according to quantity of coffee consumed within age groups

\begin{tabular}{|c|c|c|c|c|c|c|c|c|}
\hline \multirow{2}{*}{\multicolumn{5}{|c|}{ Coffee-drinking habits }} & \multicolumn{4}{|c|}{ Age groups } \\
\hline & & & & & \multicolumn{2}{|c|}{$20-29$} & \multicolumn{2}{|c|}{$30-60$} \\
\hline \multirow{4}{*}{$\begin{array}{l}\text { Like } \\
\text { Unlike }\end{array}$} & & \multirow{4}{*}{\multicolumn{2}{|c|}{. }} & & $\mathrm{MZ}$ & $\mathrm{DZ}$ & MZ & $\mathrm{DZ}$ \\
\hline & & & & & $\begin{array}{r}\text { II } \\
5\end{array}$ & $\begin{array}{r}4 \\
14\end{array}$ & $\begin{array}{r}13 \\
5\end{array}$ & $\begin{array}{r}6 \\
20\end{array}$ \\
\hline & & & & & 16 & 18 & 18 & 26 \\
\hline & & & & & \multicolumn{2}{|c|}{$\chi_{[1]}^{2} \quad 5.670 \quad P<0.02$} & \multicolumn{2}{|c|}{$x_{[1]}^{*} 9.679 \quad \mathrm{P}<0.01$} \\
\hline
\end{tabular}

MZ twins included in our examination are younger on the average and, as we have seen, smoke more than DZ twins. As regards alcohol consumption it may be noted that, when our observations are made separately for the two age groups, the difference between $M Z$ and $\mathrm{DZ}$ twins increase in the $30-60$ group, while still remaining below the 
level of significance, as indeed one might expect from our previous analysis.

It may be thought that the $M Z$ twins we interviewed lived together more often than the $\mathrm{DZ}$ twins and that this more than any genetic factor could determine greater concordance between them. To test this we have subdivided our pairs according to whether they have the same address or different addresses and have re-grouped them into similar or dissimilar according to the quantity of consumed products, which appears to be the most sensitive of all the partitions employed. The results are shown in table $2 \mathrm{r}$.

TABLE 21

Residence and concordance of smoking habits by twin pairs according to the quantity of smoked products

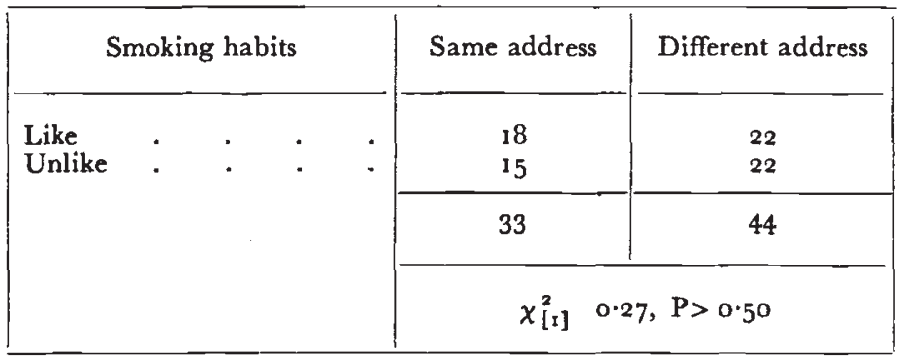

The $\chi^{2}$ value of table $2 \mathrm{I}$ is not significant. This indicates that, concerning smoking habits, there is no difference between the behaviour of the observed pairs considered in relation to their proximity of residence.

Similarly we have ascertained that there is no effect of residence on consumption of alcoholic products and coffee.

The same analyses were repeated within age classes and we have confirmed that there is no effect of age or of residence on smoking or alcohol- and coffee-drinking habits. To strengthen the evidence we have conducted the analysis on habits with respect to concordance in $\mathrm{MZ}$ and $\mathrm{DZ}$ twins separately for those which have the same residence and those which have different residences. Our further analyses have thus confirmed the conclusions drawn from table 16 , namely that there is a higher concordance in MZ twins both for smoking habits and for coffee consumption and that the difference between $\mathrm{MZ}$ and $\mathrm{DZ}$ twins is significant.

We have also analysed the answers given to the question as to whether twins are satisfied with their twin status. It may be thought that the fact of being twins, in so far as it is rare, can be considered in some sense abnormal and therefore may favour the creation of special psychological attitudes. One might expect that regarding the difficulties of life, the fact of being a twin might be considered more unfavourable the more similar are the members of a pair. 
This expectation is not in fact borne out by the observations.

Indeed, as one can see from table 22, MZ twins are more often satisfied with their twin status.

TABLE 22

Classification of twins according to whether they are satisfied or not with their twin status

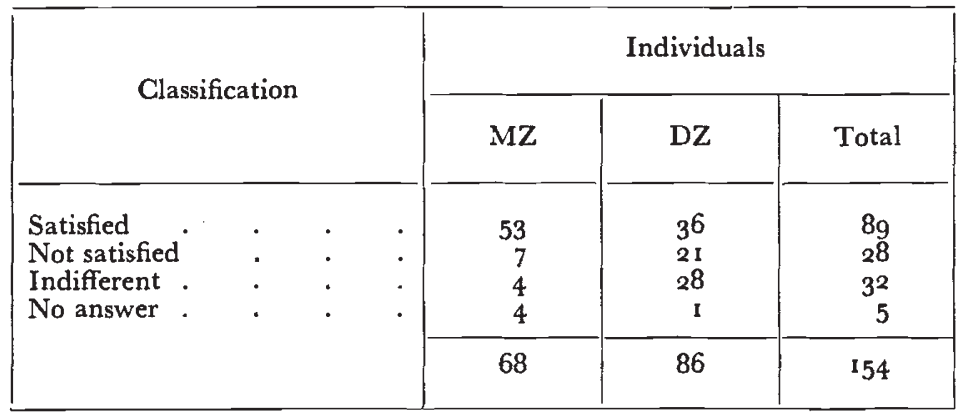

Between MZ twins, 53 out of 68 (77.9 per cent.) gave an affirmative answer while between the $\mathrm{DZ}$ twins the same answer was given by only 36 out of 86 individuals (4I.9 per cent.) and the $\chi_{[1]}^{2}$ value (I8.8I4) is highly significant $(\mathrm{P}<0.001)$. We have also analysed the concordance in the answers of the two types of twins, classifying as similar those who gave the same answer (see table 23).

\section{TABLE 23}

Analysis of concordance between $M Z$ and $D Z$ according to classification of table 22 (degree of satisfaction of being a twin)

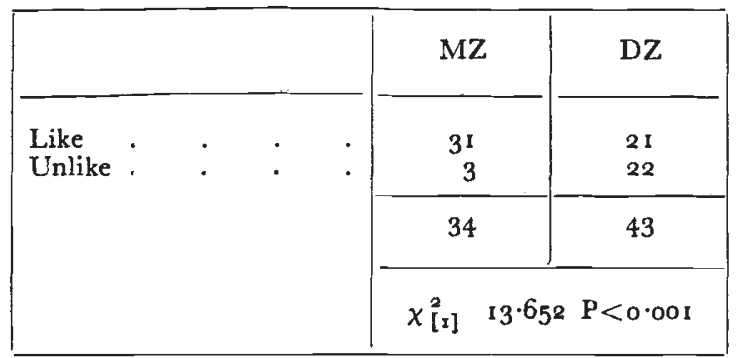

The $\chi^{2}$ calculated in this table is highly significant in relation to the higher concordance of $\mathrm{MZ}$ twins in these answers, but this might be an effect of age and of the tendency of these monozygous twins to reside together. We have therefore repeated the analysis of the difference in concordance between $\mathrm{MZ}$ and $\mathrm{DZ}$ twins within age classes and the results were unequivocally in favour of a higher concordance of $\mathrm{MZ}$ twins. The same analysis was carried out for pairs that reside together and pairs that do not reside together and the 
$\chi^{2}$ obtained was not significant. We may therefore conclude that age and proximity of residence have no detectable effect on the answer to the question whether they are satisfied or not with their twin status.

Thus from our data it seems that there is definitely a higher concordance of $\mathrm{MZ}$ twins at least regarding the consumption of cigarettes and of coffee; and this conclusion is in agreement with the results of the earlier authors. We are unable to reach a similarly confident conclusion with respect to the consumption of alcoholic beverages: a greater concordance is observed but is not statistically significant. The disagreement with Kaij's data can probably be explained by the qualitative and quantitative difference existing between the alcohol consumption of Sweden and of Italy.

\section{SUMMARY}

An enquiry was carried out to ascertain if the differences in smoking, alcohol- and coffee-drinking habits have been influenced to any important extent by hereditary factors.

For this purpose, information about the smoking and drinking habits of 77 pairs of adult male twins of Parma, Pavia and Florence were collected.

The analyses were based on the answers of 34 pairs of $M Z$ twins and 43 pairs of $\mathrm{DZ}$ twins.

The twins were classified as like and unlike in their smoking, alcoholand coffee-drinking habits.

Several factors (age, proximity of residence, satisfaction with the twin status) which might be thought to have affected the comparability or representativeness of our data are considered.

Our results allow us to conclude that there is more concordance of smoking and coffee-drinking habits in monozygotic than in dizygotic twins.

This greater concordance is apparent but it is not statistically significant in respect of habits of alcohol consumption.

\section{REFERENCES}

FISHER, R. A. 1958a. Lung cancer and cigarettes? Nature, I82, I08. FISHER, R. A. I958b. Cancer and smoking. Nature, 182, 596.

kAIJ, L. 1957. Drinking habits in twins. Acta Genet., 7, 437-44I.

MAYNARD SMITH, S., AND PENROSE, L. s. 1955. Monozygotic and dizygotic twin diagnosis. Ann. of Eugen., 19, 273-289.

PENROSE, L. S. 1947. Some notes on discrimination. Ann. of Eugen., 13, 228-237.

PENROSE, L. S. 1954. Distance, size and shape. Ann. of Eugen., 18, 337-343.

TODD, G. F., AND MASON, J. I. 1959. Concordance of smoking habits in monozygotic and dizygotic twins. Heredity, 13, 41 7-444. 